\title{
APRESENTAÇÃO
}

\section{Pluralidade e Diversidade das Ciências Sociais: uma contribuição para a epistemologia da ciência}

\author{
“O que está em jogo não é a transmissão daquilo \\ que se inventa, mas antes a transmissão do poder \\ de inventar" (Juan David Nasio). \\ "Ler uma boa página antes de se pôr a trabalhar \\ [...] a leitura é para nós iniciadora, cujas chaves \\ mágicas abrem, no fundo de nós mesmos, a porta \\ das moradas onde não saberíamos penetrar" \\ (Marcel Proust).
}

Este número da revista Sociedade e Estado contempla o tema das inovações no campo da metodologia das ciências sociais, constitui-se uma tentativa de discutir não apenas sobre os rumos que assumem as novas propostas metodológicas no campo da produção de conhecimentos nessa área, mas também de incentivar os debates sobre alguns problemas epistemológicos, teóricos e metodológicos.

Como afirma Lakatos (1993), o respeito que o homem sente pelo conhecimento constitui-se uma de suas características mais peculiares. O conhecimento, em latim, é denominado de scienta e ciência acabou tornando-se o nome de uma das mais consideradas e respeitadas formas de conhecimento. $\mathrm{O}$ que diferencia o conhecimento científico da ideologia, da superstição e das pseudociências? A igreja católica excomungou os copernicanos, e o Partido Comunista perseguiu os mendelianos por considerar suas doutrinas pseudocientíficas (Ianni, 2001). 
Há mais de quatro séculos, a ciência vem progressivamente dominando o pensamento ocidental, suplantando outras formas de conhecer e de explicar a realidade. Entretanto, este domínio de mistificação da ciência no contexto da revolução científica e técnica, com profunda penetração nas mais diversas esferas da vida social, também gerou o seu contrário: uma crítica à sua própria natureza. A este propósito, recentemente afirmou Abramovay (2004, p. 10):

A ciência retira sentido do mundo, já que faz dele um 'cosmos de causalidade natural', algo perfeitamente explicável e, portanto, desprovido de mistério. Ao mesmo tempo, a ciência se caracteriza exatamente pela impossibilidade de uma visão única, completa, acabada a respeito dos fenômenos que estuda: é provisória por definição e, portanto, é aí que reside exatamente sua força, que consiste sempre em ser superada por novos avanços.

A demarcação entre ciência e pseudociência não é apenas de ordem filosófica, tem também importância ético-política e epistemológica (Ianni, 2001). No plano ético, critica-se o seu significado social e político, denunciando-se as conseqüências do desenvolvimento científico e tecnológico em relação à qualidade de vida. Enfatiza-se aqui a impotência da ciência frente aos dilemas e problemas do homem e sua busca de felicidade e realização. $\mathrm{O}$ conhecimento científico tanto pode promover a criação como a destruição de forças sociais, a riqueza dos indivíduos e das nações, assim como fomentar as desigualdades e a pobreza. Assim,

(...) a ciência não é capaz de fornecer respostas a questões essenciais a respeito do sentido da vida ou da morte, por exemplo. Buscar na ciência a receita para a conduta individual ou social é abrir o caminho para o totalitarismo. O cientista não é um formador de utopias, e sim alguém cuja contribuição social está em sua capacidade crítica, na elaboração e utilização de conceitos [e métodos] que permitam compreender inclusive as utopias como fenômenos sociológicos. (Abramovay, 2004, p. 11).

Portanto, cabe ao cientista social declarar guerra a qualquer forma ou versão de dogmatismo, no sentido de que o pesquisador esteja atento para não assumir, como base de suas análises da realidade, paradigmas fechados e auto-suficientes. A exigência é de uma postura aberta e crítica. 
No plano epistemológico, são discutidos os padrões de análise científica atualmente em uso nas ciências sociais. Em primeiro lugar, as noções de certeza e determinação, estabelecidas nas ciências exatas e incorporadas nas ciências sociais, têm sido cada vez mais criticadas. Da mesma forma que a natureza e diversidade de objetos de estudo das ciências sociais sugere a busca de novas estratégicas teóricometodológicas, impõe-se também uma reflexão mais aprofundada sobre a cientificidade dos discursos produzidos por estas ciências. Estes temas constituem-se objeto de análise das próximas seções.

\section{A certeza e a incerteza nas ciências}

Prigogine, químico russo-belga, falecido em 2003, destacouse pela tentativa de pensar a superação do conceito de ciência elaborado a partir das contribuições centrais de Newton no século XVII. Batizou a tentativa com o nome de "Nova Aliança", numa clara alusão bíblica à relação entre homem (ciência) e natureza. Em Newton, a relação fora pensada em termos de dominação do homem sobre a natureza, em decorrência do conhecimento das leis básicas que a regem. Prigogine pensa em termos de uma nova aliança, em que ciência e natureza poderiam relacionar-se diferentemente, mediadas pela noção de caos. O caos é um componente da natureza, da mesma forma como a determinação. A relação deveria ser pensada em outros termos, numa combinação em que seria possível manter o conhecimento científico, a formulação de leis e o determinismo, mas dentro de limites de imprevisibilidade, portanto, de caos.

Na história das ciências, elaborou-se uma epistemologia que separava o campo do social do campo do natural. O primeiro estaria sujeito a múltiplas interferências, o que torna difícil, senão impossível, a aplicação de conceitos como leis e determinações, a não ser sob condições muito particulares. As ciências sociais constituem o campo da indeterminação, pois os sujeitos humanos nascem dotados de vontade, liberdade e poder de escolha, mesmo sob as mais duras condições de existência e sob as condições estruturais mais impositivas. Já o campo das ciências naturais seria objeto do 
conhecimento positivo, da determinação. Assim foram pensadas e concebidas as ciências sociais durante um século.

Tal separação entre ciências sociais e ciências naturais deu azo a toda sorte de elucubrações e permitiu efeitos reativos, que afetaram o campo das ciências sociais. A saber, sob tal paradigma, as ciências sociais não eram consideradas ciências na mesma medida que os demais campos científicos, pois o campo das ciências foi sempre o campo do verificável, do comprovável, da objetividade, da positividade. Restaria às ciências sociais contentarem-se em fazer parte do campo das humanidades e das artes, o que não implicaria demérito, dado que as ciências sociais tratam de gente e não de coisas.

A revolução proposta por Prigogine consistiria em repensar a divisão entre ciências naturais e ciências sociais, permitindo uma aproximação em outro patamar. A divisão entre ciências sociais e naturais poderia, em alguma medida, ser superada, porque as ciências da natureza também enfrentariam restrições semelhantes às primeiras, em função do caos e da imprevisibilidade. À medida que combina caos com determinação, o autor se aproxima de alguma maneira das ciências sociais, cujos paradigmas limitam o emprego das noções de determinação e de leis cientificas, formuladas de maneira absoluta.

A determinação seria pensável dentro de certos espaços ou ambientes sujeitos à ação do caos e da imprevisibilidade. Em tais condições, seria viável importar das ciências sociais categorias incomuns às ciências da natureza, tais como história, tempo, mudança, para com elas pensar as ciências da natureza. Prigogine (2002, p. 82) argumenta que

no mundo que nos cerca, constatamos a existência de objetos que obedecem a leis clássicas deterministas e reversíveis, mas correspondem a casos simples, quase exceções, como o movimento planetário de dois corpos. De resto, dispomos de objetos a que se aplica o segundo princípio da termodinâmica; eles são, aliás, a imensa maioria. É preciso, pois, que haja, mesmo independentemente da história, uma distinção cosmológica entre estes dois tipos de situação, ou seja, entre estabilidade, por um lado, e instabilidade e caos, por outro.

É um fato auspicioso que as ciências naturais tenham produzido argumentos e demonstrações que podem nos indicar os limites no 
conceito de ciência elaborado a partir dos séculos XVII e XVIII e que propiciam elementos, senão para superá-lo, pelo menos para perceber suas fragilidades. Os esforços dos pesquisadores das ciências naturais são imprescindíveis para demonstrar as fragilidades dos postulados básicos do determinismo e do positivismo, pois as ciências sociais construíram sua identidade a partir da contestação a estas premissas.

Prigogine é apenas uma voz entre outras na tentativa de repensar a epistemologia da ciência e a relação entre ciências sociais e naturais. Os cientistas naturais que operam com os conceitos de caos e de probabilidade enfrentam necessariamente este problema. Gostaríamos, ainda, de destacar contribuições do campo das ciências sociais, voltadas para mudanças paradigmáticas. Após o debate sobre as revoluções científicas, proporcionado pelas idéias propostas por Kuhn (1975), autores pós-modernos envolveram-se em repensar a crise das ciências sociais e o futuro das ciências.

Santos (2000) é um destes personagens. A tese do autor é de que o caminho da cientificidade, trilhado mediante a elevação ao máximo dos recursos objetivantes fornecidos pelas metodologias, chegou a um impasse. A saída do impasse, a seu ver, deve ser procurada em outro caminho e não dentro dos mesmos parâmetros fornecidos pelo que o autor denominou de "primeira ruptura epistemológica". Daí a necessidade de uma "segunda ruptura epistemológica", que busca aproximar aquilo que estava distante e recompor com outro sentido a operação científica.

Percebemos uma proximidade muito grande entre a proposta desta "segunda ruptura epistemológica" e a proposta de Prigogine de uma "Nova Aliança". A despeito dos diferentes pontos de partida, o primeiro das ciências sociais e o segundo das ciências naturais, ambos buscam uma saída para a crise paradigmática das ciências, e suas proposições convergem em muitos aspectos. Em meio à discussão sobre ciência, Santos trata da relação entre ciências sociais e naturais. As ciências naturais convergiriam para as ciências sociais, já que as últimas são consideradas filosoficamente anteriores.

A partir das proposições de Prigogine, poder-se-ia acrescentar mais um elemento de convergência. As próprias ciências naturais estão 
incorporando elementos de imprevisibilidade e de instabilidade, como decorrência de seus programas de pesquisa.

Santos aponta para a necessidade de novos parâmetros epistemológicos para a ciência, mas não consegue oferecer uma construção da qual possam ser retiradas conseqüências práticas sobre o modo de construir o conhecimento. Embora seja válida a afirmação que as ciências sociais precedem filosoficamente as ciências naturais, isso não garante que as primeiras indicarão o caminho do desenvolvimento futuro das ciências. Igualmente, a afirmação de que o vetor vai das ciências naturais para as ciências em geral tem amparo filosófico à medida que toda a ciência deve favorecer, em última instância, o desenvolvimento humano, mas tampouco implica que as ciências naturais indicarão o caminho do desenvolvimento futuro das ciências.

A análise contemporânea da crise dos paradigmas científicos traz para o centro do debate a questão da certeza e da incerteza. Dentro do pensamento clássico, o avanço da ciência abriria caminho para a redução das incertezas. Já no pensamento contemporâneo procura-se analisar a certeza e a incerteza de maneira mais relativa. Os autores voltam a insistir que a incerteza é um componente intrínseco dos produtos humanos, entre eles da ciência. A certeza obtida mediante o avanço científico abre imediatamente espaço para novas incertezas e novos problemas. ${ }^{1}$

O avanço do debate sobre a categoria da incerteza situa-se mais nas questões próprias da ciência enquanto tal do que na sustentação da fundamentação filosófica de que toda a ciência é produto humano e, enquanto tal, falível e produtor de ambigüidades. A busca humana volta-se por resultados das ciências cada vez mais confiáveis e seguros. Também é humano que se procure superar os níveis de incerteza. É o caso das pesquisas biológicas ou na área de saúde. Ainda que a pesquisa humana esteja embebida pela incerteza, as pessoas requerem da ciência que dê conta de suas fraquezas, de suas necessidades, de suas doenças, enfim, que coloquem num ponto

\footnotetext{
Em 2003, Demo lançou Certeza da incerteza: ambivalências do conhecimento e da vida; em 1996, Prigogine publicou $O$ fim da certeza - são livros que demonstram como a questão ganhou espaço na atualidade.
} 
distante o risco da morte. Se a ciência é eminentemente incerta, o desejo dos seres humanos é que se consiga a máxima certeza possível. Aos portadores do vírus da AIDS ou de doenças degenerativas interessa resultados de pesquisas que lhes dêem chances de sobrevida, fato que é bem diferente do que saber que a vida é essencialmente finita. No mundo da incerteza, busca-se agarrar o salva-vidas da certeza.

Ainda estamos distantes de ter chegado a um novo conceito epistemológico de ciência. Nos últimos decênios, várias brechas vêm sendo abertas e alguns limites do conceito clássico expostos. Entretanto, ainda estamos longe de ter realizado construções suficientemente integrativas de um novo paradigma para pensar a ciência e sua relação com a sociedade. Percebe-se que há um processo em marcha, mas as descobertas ainda não resultaram no novo paradigma esperado. Tal constatação só deve estimular a que esforços subsequientes sejam realizados em busca de um conceito de ciência adequado às pesquisas no início do terceiro milênio.

A relação entre ciências naturais e ciências sociais constituise um dos aspectos mais ressaltados na discussão contemporânea. Ao considerar esta relação, parece que chegamos a uma encruzilhada sem retorno, que contém sentido extremamente positivo.

A forma de conceber as ciências naturais aproxima-se da forma de conceber as ciências sociais. O grande desafio está na natureza de tal aproximação. Não há perspectivas de que atingiremos uma fusão, retornando a um único conceito de ciência, pois as características próprias dos campos do conhecimento não desaparecem apenas porque se procura vê-las uniformemente. As ciências sociais são intrinsecamente constituídas pelo grau de liberdade, de autonomia, de escolha dos seres humanos. A introdução de categorias próprias das ciências sociais, tais como tempo, história, evolução, mudança, e a adoção do raciocínio probabilístico, indica alguma aproximação em determinados aspectos, mas não que estejamos atingindo um conceito de ciência enquanto empreendimento único e universal. Se os conhecimentos das coisas devem convergir para o desenvolvimento humano, dessa afirmação não procede que os conhecimentos das gentes e das coisas são feitos da mesma maneira. 
Se a combinação de caos com determinação levar a algum sucesso nas ciências naturais, tal fato terá inevitáveis implicações também dentro das ciências sociais. Assim, a epistemologia vista nessa perspectiva dicotômica entre ciências sociais e ciências naturais, construída nas ciências sociais ao final do século XIX, não só se apresenta com necessidades de reparos, como está superada pelo avanço das ciências naturais, que buscam incorporar a flecha do tempo e com ela o caos em noções de leis, determinações, irreversibilidades, como resultado de avanços das próprias ciências naturais e não como resultado do projeto das ciências sociais que tivesse se estendido até o campo da natureza. A implicação desse avanço das ciências naturais é de que as ciências sociais precisam repensar os esquemas epistemológicos separatórios. Eles não mais se sustentam, desde que as próprias ciências naturais não os mantém mais da mesma forma como formulados à maneira concebida nos séculos XVII e XVIII.

Esforços voltados a repensar a epistemologia da ciência, as relações entre as ciências sociais e naturais, a metodologia das ciências sociais, os limites e as possibilidades dos meios e dos instrumentos da pesquisa são bem-vindos nesta época de crise paradigmática.

\section{A natureza do objeto de estudo das ciências sociais}

Um desafio permanente para as ciências sociais e, sobretudo, para a Sociologia diz respeito à própria natureza de seu objeto: é dinâmico, está sempre em movimento, em fermentação, tornando-se cada vez mais complexo, demandando novos recursos de reflexão, assim como outras estratégicas metodológicas e técnicas de análise. Configura-se com novos significados, alargando suas fronteiras para outros campos disciplinares, articula-se e desarticula-se com as ciências da natureza e do espírito. Combinam-se diferentes temporalidades e lugares, revelando desenvolvimentos desritmados, descompassados e desiguais. Articulam-se as tradições e a história com os tempos futuros e mediáticos (Ianni, 2001; Geymont \& Giorello, 1986).

Além disso, o objeto de estudo das ciências sociais mescla indivíduos e comunidades, classes e grupos sociais, gêneros e raças/ 
etnias, religiosidades e ecologia, identidades e diversidade, realidades e imaginários, regiões e nacionalidades. Confronta e agrupa indivíduo e sociedade, natureza e sociedade. Percorre as diversas forças e formas de divisão social, sexual e técnica do trabalho e da produção. Diferencia a parte do todo, o singular do universal, o público do privado, assim como a democracia, da tirania e da revolução. Confronta as guerras de classe, fundamentalismos religiosos, as guerras étnicas, promovendo tanto a destruição como a criação de riquezas entre os indivíduos e as nações (Ianni, 2001).

Além dos tradicionais objetos de estudo, novos fenômenos e questões também se oferecem às ciências sociais, como: corpo, esporte, lazer, tradução, artes, música etc. Todos precisam ser acolhidos e tratados pelas ciências sociais, pois todas as formas de expressão humana devem constituir-se como parte do complexo objeto de estudo sociológico. Assim, uma vez que a configuração da realidade social sofreu profundas transformações e os instrumentos de que se dispunha para explicar a realidade já não respondem a contento, é imperativo que novas abordagens teórico-metodológicas sejam desenvolvidas.

Em síntese, cabe ao pesquisador enfrentar as dificuldades de caracterizar essa estonteante variedade de conceitos, muitos dos quais referem-se à emergência de um novo tipo de organização social. Assim, esse elenco de fenômenos e de questões impõe que sejam desenhadas distintas abordagens epistemológicas, bem como novas estratégias teóricas e metodológicas. Esses "objetos" apresentam-se radicalmente diversos daqueles predominantes até a primeira metade do século $\mathrm{XX}$, quando o trabalho constituía-se uma das categorias sociais ordenadoras e o Estado exibia o caráter de instrumento de dominação de forma mais nítida. Hoje, o mundo é bem mais complexo, dinâmico e diversificado, exigindo que a ciência responda a essa complexidade, a fim de poder

[...] pensar a sociedade como pluralidade de dimensões entrecruzadas, dimensões que não possuem essência própria e fixa, mas que fazem e se desfazem ao sabor das múltiplas ações dos sujeitos individuais e coletivos que assim se afirmam estritamente no momento de luta, mas que não mais constituem uma figura plena, homogênea, estruturada, racional e integrada. (Bruni, 1988, p. 31) 
A Sociologia, como as demais ciências sociais, se obriga a multiplicar e diversificar seus moldes de linguagem, de teoria, seus conceitos e categorias, assim como as modalidades de descrições, explicações, suas estratégias e procedimentos metodológicos. Nesse sentido, as ciências sociais estão permanentemente desafiadas a criar e recriar meios, modos e condições para coletar informações e interpretar acontecimentos, assim como relações, processos, estruturas, conflitos e hegemonias. Essa pluralidade de objetos, teorias e métodos, já não pode mais ser respondida apenas pelos autores clássicos da teoria social, pois, segundo Dubet (1996, p. 11-12), "a extrema diversidade dos modelos, dos métodos e dos objetos, resulta do estilhaçamento de uma sociologia 'clássica' que poderíamos identificar, em larga medida, e não sem arbitrariedade, com as obras de Durkheim e de Parsons". Em outras palavras, trata-se da incapacidade dos antigos paradigmas de dar conta de toda a realidade social.

É, pois, na vastidão desse cenário que florescem novas formas de pensamento, teorias e metodologias, com o intuito firmado de sempre buscar compreender, conhecer e explicar as continuidades e descontinuidades das relações, dos processos e das estruturas sociais. Assim, as ciências sociais estão permanentemente desafiadas a ingressarem em novo ciclo de criação e de controvérsia, a partir da busca de novidades e de outros horizontes futuros que o conhecimento pode proporcionar para além de algumas das orientações teóricometodológicas usuais no domínio das ciências sociais, como, por exemplo, as perspectivas sistêmica, fenomenológica e histórica (Ianni, 2000).

As novas formulações teóricas e debates metodológicos não são unânimes; apresentam-se num campo disperso e plural. É certo que a existência de uma multiplicidade de paradigmas ou a diversidade de modelos é problemática, na medida em que questiona a capacidade das ciências sociais - e da Sociologia, em especial em manter o diálogo crítico que lhe fundamenta a unidade e o dinamismo. Enquanto alguns autores privilegiam a modernidade, outros se alinham ao discurso da pós-modernidade. Independente ou não do declínio das fronteiras civilizatórias e dos universalismos culturais, reafirma-se 
(...) a relação entre a epistemologia e o reconhecimento da presença do 'fator histórico' (...), pois, todo o conhecimento se encontra sempre historicamente 'imerso' num determinado patrimônio cognitivo: o conhecimento não é realmente um processo individual de uma teórica consciência em geral, mas o resultado da atividade social, uma vez que o patrimônio cognoscitivo já acumulado vai além dos limites a que o próprio indivíduo está sujeito. (Lakatos 1993, p. 142)

\section{A argumentação sociológica}

O trabalho sociológico pode ser, em boa medida, tomado como uma argumentação ou um discurso. Santos (2000) chega a propor que consideremos as ciências sociais como um novo tipo de retórica. $\mathrm{Ou}$ seja, é uma argumentação que busca persuadir através de verdades objetivas, de descrições e de regularidades. O cerne da proposição de Boaventura consiste naquilo que pode ser sintetizado na idéia de uma teoria argumentativa da ciência. A cientificidade de uma prova está em sua capacidade de convencer quanto à sua validade, primeiramente, a comunidade científica e, depois, a sociedade em geral. Santos vale-se da metáfora da platéia ou audiência, retirada do terreno da sociologia jurídica, mais especificamente do tribunal de júri, com a qual mantém estreita contribuição. Para que a teoria da argumentação não fique reduzida a um efeito espetacular de domínio do orador sobre o auditório, são necessárias aquelas condições postuladas pela filosofia da ciência para definir a verdade. São necessárias também condições em que os sujeitos estejam liberados de qualquer interesse material e voltados apenas para a busca da verdade em si. As evidências empíricas e as demonstrações matemáticas são argumentos que conduzem ao convencimento das audiências, não em função de efeitos de linguagem, mas da consistência e justeza dos argumentos.

Posto desta forma, o debate sobre ciência e senso comum, como duas formas distintas de discurso, é pertinente e necessário para entender as especificidades de cada um deles. O discurso científico não é uma argumentação qualquer, é direcionado a uma comunidade de juízes especialistas e, portanto, deve ser o mais preciso possível. É a necessidade de objetivação que diferencia o argumento científico dos outros tipos de discurso. Em outras palavras, para que um 
argumento seja considerado científico é necessário que a comunidade para a qual o pesquisador se dirige entenda precisamente a problemática tratada e as inferências realizadas a partir dos fatos observados. Ser compreendido é o requisito básico de um trabalho sociológico. Isso não quer dizer que a comunidade de especialistas irá concordar com a argumentação realizada, mas que foi estabelecida a possibilidade de diálogo.

Se por um lado, sustentamos o caráter específico do discurso científico, por outro precisamos reconhecer a multiplicidade de discursos científicos. Não nos referimos apenas às diferenças entre o conhecimento produzido pelas ciências naturais, biológicas, da terra e humanas. Dentro de uma mesma área, podemos constatar uma diversidade de argumentos igualmente válidos do ponto de vista da objetividade. Este é o caso das ciências sociais. Frequientemente encontramos explicações distintas sobre um mesmo fenômeno que, não raro, chegam a ser antagônicas.

Embora distintas, estas explicações comungam de algumas características comuns além da objetividade. Elas são essencialmente argumentativas e, portanto, compartilham da mesma estrutura discursiva de uma argumentação científica. Basicamente, podemos dizer que uma argumentação em ciências sociais é constituída de: a) uma afirmação; b) de evidências empíricas que sustentam esta afirmação; e, c) dos fundamentos teóricos que relacionam a afirmação às evidências (Toulmin, 2001). As variações encontradas nos diferentes tipos de argumentação sociológica dependem da metodologia de pesquisa adotada, da abordagem teórica empregada e das evidências empíricas apresentadas.

Uma das questões mais delicadas numa argumentação sociológica é a elaboração e o teste de hipóteses. Este irá depender do tipo de pesquisa que se pretende realizar. Inúmeras pesquisas que utilizam metodologias quantitativas buscam, dentre outras coisas, verificar as relações entre duas ou mais variáveis. Para isso, constróise um banco de dados, com diferentes variáveis e empregam-se técnicas estatísticas para aferir o grau de correlação entre elas. Neste caso, a hipótese é uma afirmação sobre as relações entre variáveis levantadas a partir de uma abordagem teórica específica. 
O teste de hipóteses, entretanto, é mais difícil de ser realizado se o pesquisador utilizar outras metodologias diferentes da abordagem quantitativa. Numa pesquisa qualitativa, na qual o pesquisador busca interpretar ou explicar um determinado fenômeno social, dificilmente poderíamos falar em teste de hipóteses. Da mesma forma, numa pesquisa comparativa, que procure descobrir variações de um determinado fenômeno social, não cabe testar hipóteses.

Apesar das diferenças, as abordagens quantitativas, qualitativas e comparativas têm em comum o fato de partirem de uma afirmação que deverá ser sustentada com base em evidências empíricas. O teste de hipótese é apenas uma das formas de sustentar esta afirmação inicial.

Embora a afirmação seja o centro da sua argumentação, a maior parte da pesquisa em ciências sociais é dedicada à coleta e demonstração das evidências empíricas. As evidências dão sustentação ao argumento sociológico. Dada a sua importância num trabalho científico, cabe perguntar: Quais os critérios de validade de uma evidência empírica? Em outras palavras, o que é uma evidência válida?

A resposta a esta pergunta é bastante complexa. Antes de tudo, é necessário entender o caráter transitório dos critérios, cuja validade é estabelecida pela comunidade epistemológica a que pertence o pesquisador. Uma evidência empírica aceita como válida por uma comunidade pode não ser por outra. Isso não quer dizer que uma comunidade epistemológica tenha critérios de validade mais rigorosos do que as outras comunidades. Apenas que determinados fatos ou dados apresentados não servem para sustentar aquelas afirmações. Diferentes comunidades epistemológicas fazem diferentes perguntas e afirmações que, portanto, necessitam de diferentes tipos de evidências.

Vejamos alguns casos. Uma pesquisa quantitativa que busque relacionar a origem social dos pais à profissão que o filho irá exercer. As evidências utilizadas nesta pesquisa serão extraídas de surveys previamente realizados (as PNADs, por exemplo), bem como as relações propostas serão baseadas em modelos de correlação estatísticos. Neste caso, a validade das evidências dependerá, em boa medida, da metodologia empregada na coleta destes dados e da 
adequação dos modelos estatísticos utilizados. Normalmente, os trabalhos que utilizam este tipo de evidência trazem uma competente descrição das fontes de dados, das metodologias de coleta e dos modelos estatísticos empregados.

Outro exemplo. Uma pesquisa sobre a discricionariedade na atividade policial. Para verificar como os policiais utilizam o seu poder discricionário, o pesquisador realizou uma etnografia e, para isso, acompanhou os policiais em diferentes situações de trabalho. A validade das observações utilizadas como evidências dependem da clara explicitação das condições destas observações. Ou seja, como fora feita a aproximação com o grupo a ser observado, qual a relação desse grupo com o pesquisador e que diálogos foram realizados durante a pesquisa. Em suma, a validade das evidências empíricas apresentadas depende das técnicas de coleta de informações empregadas. Estas técnicas variam de acordo com o tipo de afirmação que se pretende sustentar.

Uma afirmação não se relaciona diretamente com uma evidência empírica. É necessário que se use um fundamento teórico para relacionar estas duas partes da argumentação. Esta fundamentação diz respeito, portanto, à lógica da argumentação. Existem vários fundamentos, também conhecidos como abordagens teóricas, disponíveis aos cientistas sociais. Cada um desses fundamentos baseia-se em premissas e conceitos distintos.

Ao afirmar que a votação num determinado partido reflete a preferência do eleitorado pelas suas políticas propostas, estamos partindo do pressuposto de que os comportamentos observáveis refletem as preferências individuais. Entretanto, outros pesquisadores podem não concordar com estas premissas, uma vez que acreditam que os comportamentos observáveis não necessariamente refletem preferências individuais e que existe uma série de fatores que também condicionam a ação dos indivíduos, tais como: cultura, identidade e instituições.

Ou, ao contrário, quando afirmamos que a violência policial está relacionada à precariedade dos mecanismos institucionais de controle da atividade policial, estamos partindo do pressuposto de que as instituições moldam os comportamentos individuais. Nesse caso, alguns pesquisadores podem discordar alegando que mesmo as instituições são resultado de vontades individuais. 
Normalmente, os trabalhos sociológicos explicitam os fundamentos utilizados na sua argumentação. A bem da verdade, devese dizer que tanto a afirmação quanto os tipos de evidências apresentadas são deduzidos da fundamentação teórica. As divergências apresentadas nos dois exemplos referem-se aos pressupostos teóricos utilizados pelos autores. Podemos dizer que existem diferentes comunidades epistemológicas que comungam das mesmas premissas e conceitos.

É importante notar que a fundamentação teórica não responde sobre a validade das evidências apresentadas mas, sim, sobre a pertinência da afirmação. Em outras palavras, se aquela afirmação pode ser deduzida das evidências apresentadas. Naturalmente, o leitor pode rejeitar o fundamento teórico utilizado numa argumentação científica, muito embora possa reconhecer como válidas as evidências apresentadas. O que está em questão, neste caso, não é a qualidade das evidências, mas sua relação lógica com a afirmação.

A restauração da noção argumentativa no campo das ciências tem um futuro promissor por incorporar intimamente a idéia dos limites da determinação. Pesa contra ela o fato de que dissolve o campo da ciência em um problema de linguagem. A ciência se expressa por meio de linguagens, mas não se reduz a elas. Os fatos científicos são comunicados através de argumentos para platéias de cientistas e de pessoas da sociedade. Os fatos científicos operam como argumentos para convencer das certezas ou das incertezas. A teoria argumentativa da ciência procura avançar no campo de uma concepção de convencimento. Contra a tese de argumentação estaria o fato de que as pessoas que melhor argumentam podem também convencer de sofismas. Como os argumentos são formulados no campo da racionalidade, supondo que os espíritos estejam despidos de paixão e movidos apenas pela busca do melhor argumento, tal situação afasta a noção de argumento como arma do sofisma.

Sadi Dal Rosso

Lourdes Bandeira

Arthur Trindade Maranhão Costa

(Organizadores) 


\section{Referências bibliográficas}

ABRAMOVAY, Ricardo. A razão do Ocidente: o processo de racionalização em Weber. Folha de São Paulo, 14 fev. 2004, Caderno de Resenha.

BRUNI, J. C. Há uma crise nas Ciências Sociais? In: Opensamento em crise e as artimanhas do poder. São Paulo: Unesp, 1988.

DEMO, P. Certeza da incerteza: ambivalências do conhecimento e da vida. Brasília: Editora Plano, 2003.

DUBET, F. Sociologia da Experiência. Lisboa: Instituto Piaget, 1996.

GEYMONT, L.; GIORELLO, G. As razões da Ciência. Lisboa: Edições 70, 1986.

IANNI, O. Sociologia do futuro. Primeira Versão 100. Campinas, SP: Departamento de Sociologia, IFCH/UNICAMP, 2001.

IANNI, O. Enigmas da modernidade-mundo. Rio de Janeiro: Civilização Brasileira, 2000.

KUHN, T. S. A estrutura das revoluções científicas. São Paulo, Perspectiva, 1975.

LAKATOS, I. La metodología de los programas de investigación científica. Madrid: Alianza Universidad, 1993.

PRIGOGINE, I. As leis do caos. São Paulo: Ed. Unesp, 2002.

PRIGOGINE, I.; STENGERS, I. A Nova Aliança: metamorfose da ciência. Brasília: Ed. UnB, 1984.

PRIGOGINE, I. O fim da certeza: tempo, caso e as leis da natureza. São Paulo: Ed. Unesp, 1996.

SANTOS, B. S. Introdução a uma ciência pós-moderna. Rio de Janeiro: Graal, 1989.

SANTOS, B. S. A crítica da razão indolente: contra o desperdício da experiência. São Paulo: Cortez, 2000.

TOULMIN, S. Os Usos do Argumento. São Paulo: Martins Fontes, 2001. 